\title{
Exhaled and nasal NO levels in allergic rhinitis: relation to sensitization, pollen season and bronchial hyperresponsiveness
}

\author{
A.H. Henriksen*, M. Sue-Chu*, T. Lingaas Holmen*, A. Langhammer*, L. Bjermer*
}

\begin{abstract}
Exhaled and nasal NO levels in allergic rhinitis: relation to sensitization, pollen season and bronchial hyperresponsiveness. A.H. Henriksen, M. Sue-Chu, T. Lingaas Holmen, A. Langhammer, L. Bjermer. (C)ERS Journals Ltd 1999.

ABSTRACT: Exhaled nitric oxide is a potential marker of lower airway inflammation. Allergic rhinitis is associated with asthma and bronchial hyperresponsiveness.

To determine whether or not nasal and exhaled NO concentrations are increased in allergic rhinitis and to assess the relation between hyperresponsiveness and exhaled NO, 46 rhinitic and 12 control subjects, all nonasthmatic nonsmokers without upper respiratory tract infection, were randomly selected from a large-scale epidemiological survey in Central Norway. All were investigated with flow-volume spirometry, methacholine provocation test, allergy testing and measurement of nasal and exhaled NO concentration in the nonpollen season. Eighteen rhinitic subjects completed an identical follow-up investigation during the following pollen season.

Exhaled NO was significantly elevated in allergic rhinitis in the nonpollen season, especially in perennially sensitized subjects, as compared with controls $(p=0.01)$, and increased further in the pollen season $(p=0.04)$, mainly due to a two-fold increase in those with seasonal sensitization. Nasal NO was not significantly different from controls in the nonpollen season and did not increase significantly in the pollen season. Exhaled NO was increased in hyperresponsive subjects, and decreased significantly after methacholine-induced bronchoconstriction, suggesting that NO production occurs in the peripheral airways.

In allergic rhinitis, an increase in exhaled nitric oxide on allergen exposure, particularly in hyperresponsive subjects, may be suggestive of airway inflammation and an increased risk for developing asthma.
\end{abstract}

Eur Respir J 1999; 13: 301-306.

*Dept of Lung Medicine, Norwegian University of Science and Technology, Trondheim; "National Institute of Public Health, Community Medicine Research Unit, Verdal, Norway.

Correspondence: L. Bjermer

Dept of Lung Medicine

Norwegian University of Science and

Technology

N-7006 Trondheim

Norway

Fax: 4773997424

Keywords: Allergen exposure allergic rhinitis

bronchial hyperresponsiveness methacholine

nitric oxide

Received: February 111998

Accepted after revision September 291998

This study was supported by Astra Norway and the Norwegian Asthma and Allergy Association.

Previous studies have shown that a significant proportion of those with allergic rhinitis without bronchial symptoms have a bronchial hyperresponsiveness to methacholine [1$3]$. Moreover, this responsiveness seems to increase during the allergen season [3]. Thus, there seems to be a link between the existence and the severity of allergic rhinitis and the degree of responsiveness in the lower airways. The reason for this is not clear. Nasal obstruction resulting in mouth breathing, with impaired filtration and conditioning of the inspired air and increased inhalation of aeroallergens might be a cause. Another hypothesis is that inflammatory mediators may be aspirated from the inflammatory area in the nose into the lower airways, thereby causing a more widespread inflammation. Topical intranasal corticosteroid treatment reduces the release of inflammatory mediators [4], and beclomethasone dipropionate $400 \mu \mathrm{g}$ daily is more effective in preventing the seasonal increase in bronchial responsiveness when administered topically by intranasal inhalation than by oral inhalation [5]. A third explanation which must be considered is the possible presence of a nasobronchial reflex. Nasal stimulation with methacholine increases airway resistance in the nose, as well as in the lower airways [6]. Other evidence suggestive of this reflex is the increase in bronchial responsiveness to methacholine within $30 \mathrm{~min}$ of nasal challenge with an allergen [7].
Nitric oxide in exhaled air has been proposed as a potential marker of inflammation in the lower airways [8]. Increased levels of NO in exhaled air have been reported in normal individuals with upper respiratory tract infections [9] and in patients with asthma, especially those with allergic asthma $[10,11]$. A further increase can be seen in relation to asthma exacerbation, while normalization of NO levels often occurs after steroid treatment [12]. As allergic rhinitis frequently precedes the development of asthma, the primary aim of the present study was to see whether or not nasal and exhaled concentrations of NO are increased in those with allergic rhinitis, and whether the concentrations varied during and off-allergen-season. Secondary aims were to assess the relation between bronchial hyperresponsiveness and NO concentration in exhaled air and to see whether or not the methacholine provocation test itself could influence the concentration of exhaled NO.

\section{Materials and methods}

\section{Subjects}

The North Trøndelag County Health Study in Central Norway (1995-1997) invited all inhabitants aged $\geq 13$ yrs 
(105,000 people) to join the survey. As part of this, 8,499 adolescents (13-19 yrs) were investigated with a response rate of $90 \%$. The investigation consisted of a self-administered questionnaire, a structured interview conducted by specially trained nurses, a clinical examination and flow-volume spirometry. The interview dealt with asthma-related symptoms, diagnosed asthma, use of asthma medication, and the presence of upper and lower airway allergy.

During the interview, 921 (11.6\%) individuals reported allergic rhinitis without a history of wheezing, dyspnoea or use of asthma medication. From this group, a total of $156(1.8 \%)$ individuals were selected at random from two municipalities and invited for further investigation in the late autumn and winter, several months before the start of the birch or grass pollen season of 1997. Ninety-nine individuals (attendance rate 63\%) were investigated with measurement of exhaled and nasal NO levels, spirometry, methacholine provocation test and allergy-screening (Phadiatop CAP ${ }^{\mathrm{TM}}$; Pharmacia Diagnostics, Lund, Sweden).

\section{The cross-sectional study}

From this group of 99 individuals, 46 subjects were included in the cross-sectional study. They were all nonsmokers without current upper respiratory tract infection, and had a positive allergy screening blood test with sensitization to seasonal allergens (birch pollen and/or timothy grass pollen). Nineteen subjects were sensitized to seasonal allergens only (timothy grass, 18 and birch pollen, 8), while 27 subjects were also sensitized to perennial allergens such as house dust mite (20), dander from household pets (15) or mould (2). Thus, the subjects were divided into two groups according to sensitization: seasonal sensitization or seasonal and perennial sensitization. Subject characteristics are summarized in table 1 .

\section{The longitudinal study}

The 46 subjects from the cross-sectional study were recruited for a follow-up study with a similar investigation

Table 1. - Subject characteristics in cross-sectional study

\begin{tabular}{|c|c|c|c|}
\hline & \multirow{2}{*}{ Control } & \multicolumn{2}{|c|}{ Allergic rhinitis } \\
\hline & & $\begin{array}{c}\text { Seasonal } \\
\text { sensitization }\end{array}$ & $\begin{array}{c}\text { Seasonal }+ \\
\text { perennial } \\
\text { sensitization }\end{array}$ \\
\hline $\mathrm{n}$ & 12 & 19 & \\
\hline Age yrs & $17.8(16-19)$ & $16.2(13-20)$ & $16.5(13-19)$ \\
\hline Sex M/F & $5 / 7$ & $10 / 9$ & $14 / 13$ \\
\hline FEV $1 \%$ pred & 122 & 113 & $110(75-139)$ \\
\hline FVC \% pred & $114(106-127)$ & $108(82-141)$ & $106(66-140)$ \\
\hline $\begin{array}{l}\mathrm{BHR}^{+} \text {to } \\
\text { methacholine } \\
\mathrm{n}(\%)\end{array}$ & 0 & $3(16)$ & $12(44)^{\S}$ \\
\hline \multicolumn{4}{|c|}{$\begin{array}{l}\text { Data are presented as mean values with ranges in parentheses } \\
\text { unless indicated otherwise. *: Bronchial hyperresponsiveness } \\
\text { (BHR) as defined by dose-response slope }[13] ; *: p<0.05 \text { versus } \\
\text { controls, ANOVA test with Bonferroni's correction; }{ }^{\S}: \mathrm{p}=0.04 \\
\text { versus seasonal, Chi-squared test. }\end{array}$} \\
\hline
\end{tabular}

during the pollen season. Eighteen subjects, of whom ten had only seasonal and eight had both seasonal and perennial sensitization, completed the follow-up study which took place during the grass pollen season in July 1997. The remaining subjects either did not reattend (18) or were excluded because of upper respiratory tract infection within 6 weeks prior to the scheduled reinvestigation (7) or use of nasal steroids (3). All subjects were symptomatic and were on treatment with antihistamines at the time of investigation. Subject characteristics are summarized in table 2.

A control group of 12 nonsmoking subjects who did not report a history of rhinitis or asthma was recruited from the cohort and investigated in the nonpollen season. These subjects were not hyperresponsive to methacholine, had a negative Phadiatop test and did not have a current upper respiratory tract infection at the time of investigation.

All subjects, as well as the parents of those subjects $<16$ yrs of age, gave written informed consent prior to participation in the study. The study was approved by the regional ethical committee in Trondheim.

\section{Spirometry and methacholine provocation test}

Lung function was assessed by flow-volume spirometry, performed with a MasterScope spirometer, version 4.1 (Erich Jaeger, Würzburg, Germany). The methacholine provocation test was performed with automatic tidal volume triggered equipment (Jaeger APS system), which was programmed to deliver a maximal cumulative dose of $2,000 \mu \mathrm{g}$ methacholine in five increments. The test was terminated if the decline in forced expiratory volume in one second (FEV1) exceeded $20 \%$ of the baseline value. The bronchial responsiveness to methacholine was expressed as the linear slope of the dose response, which was the percentage fall in $\mathrm{FEV} 1 \cdot \mathrm{mg}$ cumulative methacholine dose $\mathrm{e}^{-1}$ [13]. Bronchial hyperresponsiveness was defined as a slope $>10 \%$ fall in $\mathrm{FEV} 1 \cdot \mathrm{mg}$ cumulative methacholine $\operatorname{dose}^{-1}[13]$.

\section{Measurement of nitric oxide}

The measurement of NO concentration in the expired and nasal air in this study was performed in accordance with the recommendations of the European Respiratory Society (ERS) Task Force Report on standardization of equipment specification and respiratory manoeuvres [14]. NO level in the nasal and exhaled air was measured by the chemiluminescence method with a LR 2000 nitric oxide gas analyser (Logan Research, Rochester, UK). Calibration of the analyser was performed with a reference calibration gas containing 118 parts per billion (ppb) NO in nitrogen ("SpectraSeal", BOC Speciality Gases, Guildford, UK) at a gas sample flow rate of $250 \mathrm{~mL} \cdot \mathrm{min}^{-1}$. Auto zero was performed prior to the acquisition of each measurement.

NO levels were measured in duplicate with the subject in the seated position. For exhaled NO measurement, a nose clip was applied immediately prior to oral inspiration to total lung capacity. With the help of a biofeedback monitor, the subject immediately commenced controlled exhalation against a target resistance of $4-5 \mathrm{~cm} \mathrm{H}_{2} \mathrm{O}$ and 
Table 2. - Lung function and bronchial responsiveness in longitudinal study

\begin{tabular}{|c|c|c|c|c|c|c|}
\hline & \multicolumn{3}{|c|}{ Seasonal sensitization $(\mathrm{n}=10)$} & \multicolumn{3}{|c|}{ Seasonal + perennial sensitization $(n=8)$} \\
\hline & Nonpollen & p-value & Pollen & Nonpollen & p-value & Pollen \\
\hline FEV1 \% pred* & $\begin{array}{c}115 \\
(91-145)\end{array}$ & 0.05 & $\begin{array}{c}120 \\
(98-138)\end{array}$ & $\begin{array}{c}108 \\
(75-126)\end{array}$ & 0.26 & $\begin{array}{c}114 \\
(82-130)\end{array}$ \\
\hline FVC \% pred & $\begin{array}{c}106 \\
(82-140)\end{array}$ & 0.07 & $\begin{array}{c}109 \\
(88-135)\end{array}$ & $\begin{array}{c}101 \\
(66-115)\end{array}$ & 0.19 & $\begin{array}{c}107 \\
(75-129)\end{array}$ \\
\hline Dose-response slope to methacholine & $\begin{array}{c}-3.8 \\
(-214--0.13)\end{array}$ & 0.14 & $\begin{array}{c}-5.6 \\
(-211--2.2)\end{array}$ & $\begin{array}{c}-4.1 \\
(-55.3-0)\end{array}$ & 0.12 & $\begin{array}{c}-10.5 \\
(-534--0.83)\end{array}$ \\
\hline
\end{tabular}

*: mean values (range); ${ }^{\star}$ : median values (range). FEV1: forced expiratory volume in one second; FVC: forced vital capacity.

at a flow rate of $250 \mathrm{~mL} \cdot \mathrm{s}^{-1}$ to residual volume. For nasal NO measurement, the subject inspired to total lung capacity through the nose and was asked to perform a breathhold for at least $15 \mathrm{~s}$, during which gas was sampled from one nostril. Breath-holding was verified by simultaneous measurement of $\mathrm{CO}_{2}$ level in the sampled air. The sampling flow rate for measurement of both exhaled and nasal $\mathrm{NO}$ was $250 \mathrm{~mL} \cdot \mathrm{min}^{-1}$.

Levels of exhaled and nasal NO were based on analysis of the plateau portion of the exhaled and nasal NO curves. The average value for each subject was used for analysis. The coefficient of variation $(\mathrm{CV})$ for exhaled $\mathrm{NO}$ and nasal NO were 11.4 and $12.2 \%$, respectively. The agreement between two independent readers was excellent for levels of exhaled NO ( $\mathrm{r}=0.99$, CV 7.1\%) and nasal NO ( $\mathrm{r}=0.96$, CV 9.5\%). All NO curves were subjected to thorough quality control, and only subjects with optimal NO curves were included in the study.

Exhaled NO levels were measured immediately after methacholine provocation in 10 allergic rhinitics with $>20 \%$ decline in FEV1 and in 10 control subjects with $<10 \%$ decline in FEV1, and again in methacholine-positive subjects at $10-15 \mathrm{~min}$ after bronchodilatation with $1 \mathrm{mg}$ inhaled terbutaline (Bricanyl Turbohaler, Astra Draco Lund, Sweden).

\section{Allergy screening}

Serum was analysed for the presence of immunoglobulin (Ig)E to a panel of eight common inhalant allergens by Phadiatop CAP ${ }^{\mathrm{TM}}$. All samples with a positive Phadiatop were analysed for the level of specific IgE against house dust mite (Dermatophagoides pteronyssinus), cat, horse, dog, timothy grass, birch, mugwort and cladosporium allergens (RAST, Pharmacia Diagnostics). The level of specific IgE is expressed on a scale of $1-5$, and a level of at least 2 was considered to be positive evidence for sensitization. The pollen season was defined as the period from the beginning of May to the end of July.

\section{Statistical methods}

Association of bronchial hyperresponsiveness with allergen sensitization was assessed by the Chi-squared test. Unpaired data on bronchial responsiveness and NO levels were assessed by the Mann-Whitney U-test and the Kruskal-Wallis test with Dunn's multiple comparison test; paired data were assessed by the Wilcoxon paired test. Unpaired and paired spirometry data were assessed by the ANOVA test with Bonferroni's correction and by the paired t-test, respectively. Correlation were assessed by calculation of the Spearman correlation coefficient. A pvalue $\leq 0.05$ was considered to be statistically significant.

\section{Results}

\section{Cross-sectional study in the nonpollen season}

Methacholine provocation and spirometry. Bronchial hyperresponsiveness to methacholine was present in 15 $(33 \%)$ subjects with allergic rhinitis (table 1). Compared with seasonal sensitized subjects, subjects with addition of perennial sensitization had a twofold greater prevalence of hyperresponsiveness $(p=0.04)$ and a significantly greater dose response slope to methacholine (median (range) -9.3 (-516.0--4.7) versus -3.7 (-214.02.2), $\mathrm{p}<0.01)$.

FEV1 and forced vital capacity (FVC) values in both control and rhinitis subjects were within the normal range (table 1). FEV1 was significantly lower in allergic rhinitis with both seasonal and perennial sensitization than in control subjects $(\mathrm{p}<0.05)$. FVC was not significantly different between the three groups.

Exhaled and nasal NO. All control subjects and 40 subjects with allergic rhinitis had technically satisfactory expired or nasal NO curves. The exhaled NO level in allergic rhinitis was 1.5 -fold greater than in controls (me-dian (range) 7.8 (3.4-45.8) versus 5.2 (2.4-8.9) $\mathrm{ppb}, \mathrm{p}=0.01)$. This increase was mainly due to those with sensitization to both seasonal and perennial allergens (fig. 1).

Nasal NO levels were not significantly different between controls and allergic rhinitis (median (range) 1,014 $(490-1,632)$ versus $1,105(551-2,051) \mathrm{ppb}, \mathrm{p}=0.73))$ or between subjects with both seasonal and perennial sensitization and those with seasonal sensitization only (median (range) 1,072 (763-1,562) versus 1,117 (551-2,015) $\mathrm{ppb}, \mathrm{p}=0.81)$. No significant correlation between exhaled NO and nasal NO levels was found in any of the groups.

Exhaled NO levels and bronchial responsiveness. The exhaled NO level in allergic rhinitis was 1.5 -fold greater in hyperresponsive subjects than in nonhyperresponsive subjects (median (range) 10.5 (3.7-45.8) versus 7.1 (3.4-41.2) ppb, $\mathrm{p}=0.03$ ) (fig. 2a). In nonhyperresponsive subjects, the exhaled NO level was significantly greater 


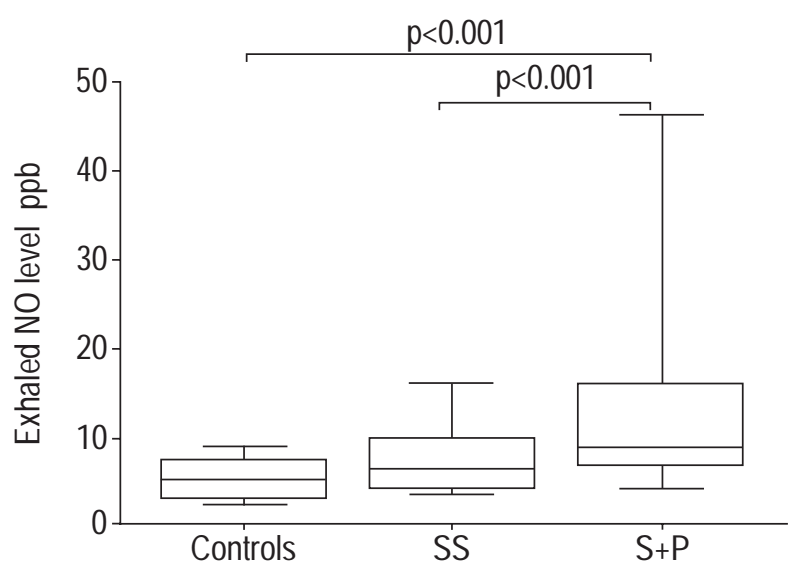

Fig. 1. - Exhaled NO levels in nonpollen season. Data from 12 controls and 40 allergic rhinitics (16 with seasonal sensitization (SS) only and 24 with both seasonal and perennial sensitization $(\mathrm{S}+\mathrm{P})$. Box and whiskers plot with median, interquartile range and minimum and maximum values. ppb: parts per billion.

in subjects with both seasonal and perennial sensitization than in those with only seasonal sensitization $(\mathrm{p}=$ 0.03 ) (fig. 2b).

Exhaled NO levels did not correlate with the doseresponse slope to methacholine $(n=52$, rho $=-0.24, p=$ 0.09 ), and in rhinitis subjects with hyperresponsiveness there was a weak correlation of exhaled NO levels with the dose-response slope $(n=11$, rho $=-0.69, p=0.02)$.

\section{Longitudinal study in the pollen season}

Methacholine provocation and spirometry. There were three subjects in each group who were hyperresponsive to methacholine in both the nonpollen and the pollen seasons. In addition, three subjects, two of whom were sensitized to both seasonal and perennial allergens, became hyperresponsive in the pollen season. In both groups, FVC and bronchial responsiveness increased in the pollen season. These changes were not statistically significant, with the exception of the increase in FEV1 in only seasonal sensitized subjects $(\mathrm{p}=0.05)$ (table 2$)$.
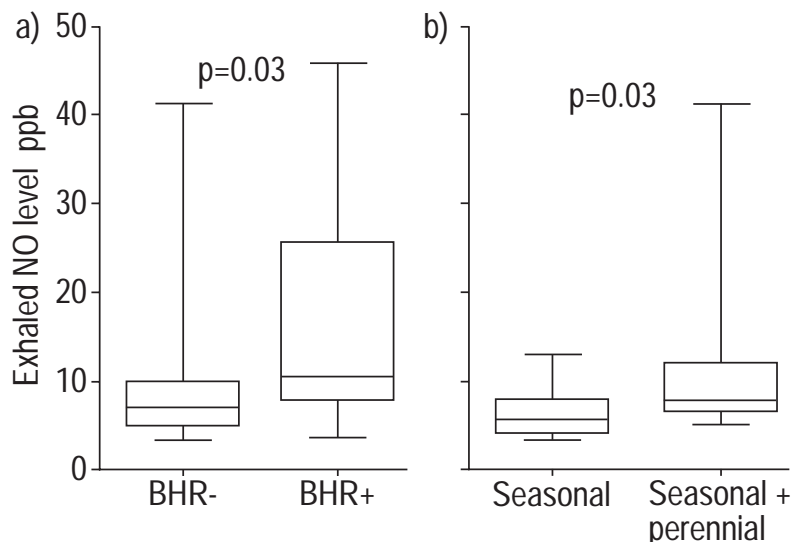

Fig. 2. - Exhaled NO level and bronchial hyperresponsiveness (BHR) in allergic rhinitis in nonpollen season. a) Data from 28 nonhyperresponsive (BHR-) and 12 hyperresponsive (BHR+) allergic rhinitics. b) Data from nonhyperresponsive subjects: 14 with seasonal sensitization only, and 14 seasonal + perennial sensitization. Box and whiskers plot with median, interquartile range and minimum and maximum values. ppb: parts per billion.
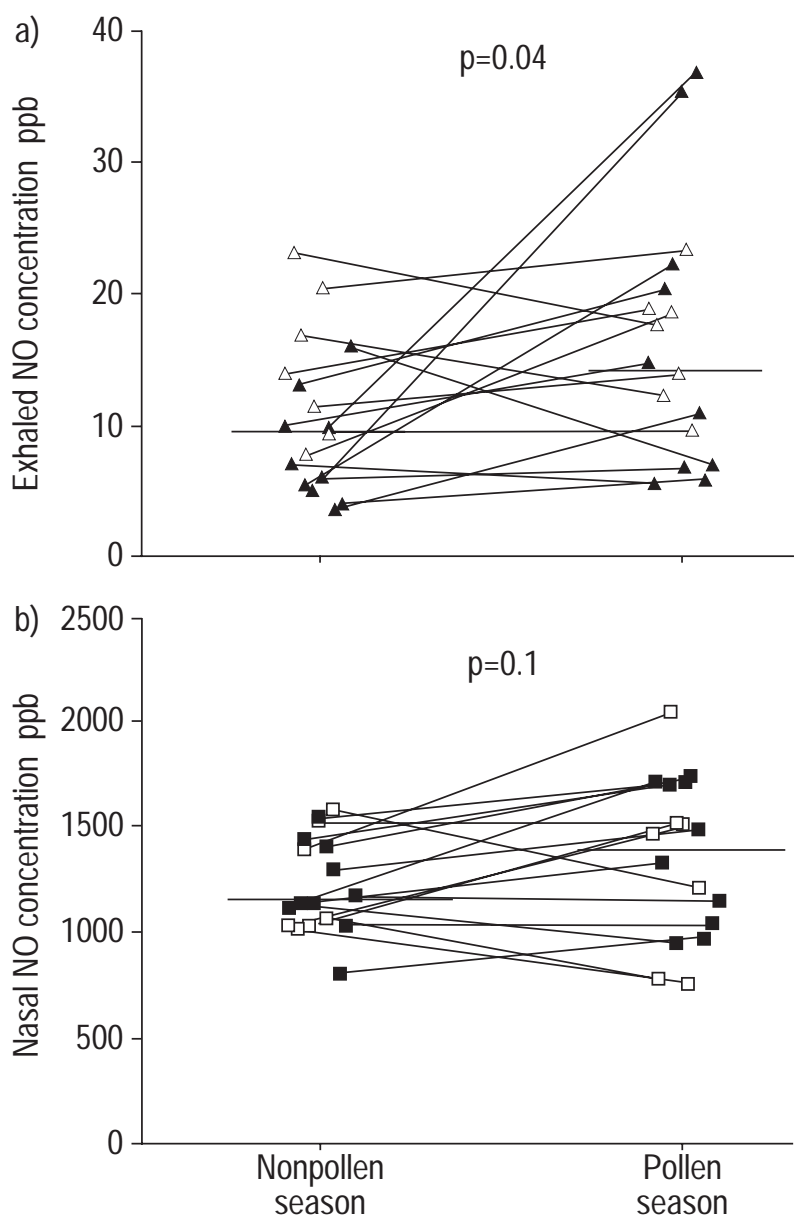

Fig. 3. - a) Exhaled and b) nasal concentrations in 18 subjects with allergic rhinitis in nonpollen and pollen seasons. Seasonal sensitization only, $\mathrm{n}=8(\boldsymbol{\Lambda}, \boldsymbol{\nabla})$, seasonal + perennial sensitization, $\mathrm{n}=10(\Delta, \square)$. Horizontal bars are the median value. ppb: parts per billion.

Exhaled and nasal NO. In allergic rhinitis, exhaled NO increased significantly between the nonpollen and the pollen season (median (range) 9.4 (3.4-22.9) versus 13.8 (5.1-36.2) ppb, $\mathrm{p}=0.04)$. This was mainly due to a twofold increase in exhaled NO in those with sensitization to seasonal allergens only (median (range) 6.4 (3.4-15.7) to $12.3(5.1-36.2) \mathrm{ppb}, \mathrm{p}=0.07$ ) (fig. 3).

The increase in nasal NO was not statistically significant (median (range) 1,073 (829-1,562) to 1,256 (740-2,004) $\mathrm{ppb}, \mathrm{p}=0.84$ ).

\section{Methacholine provocation test and exhaled NO}

In the nonpollen season, exhaled NO levels after methacholine provocation testing were significantly reduced in the ten control subjects with $<10 \%$ decline in FEV1 $(\mathrm{p}=0.004)$ and in the ten rhinitic subjects with $>20 \%$ decline in FEV1 $(\mathrm{p}=0.01)$. In the latter group, exhaled NO levels after terbutaline treatment remained significantly lower than baseline levels, despite an improvement in FEV1 (fig. 4). The exhaled NO curves from one hyperresponsive subject are shown in figure 5 . 


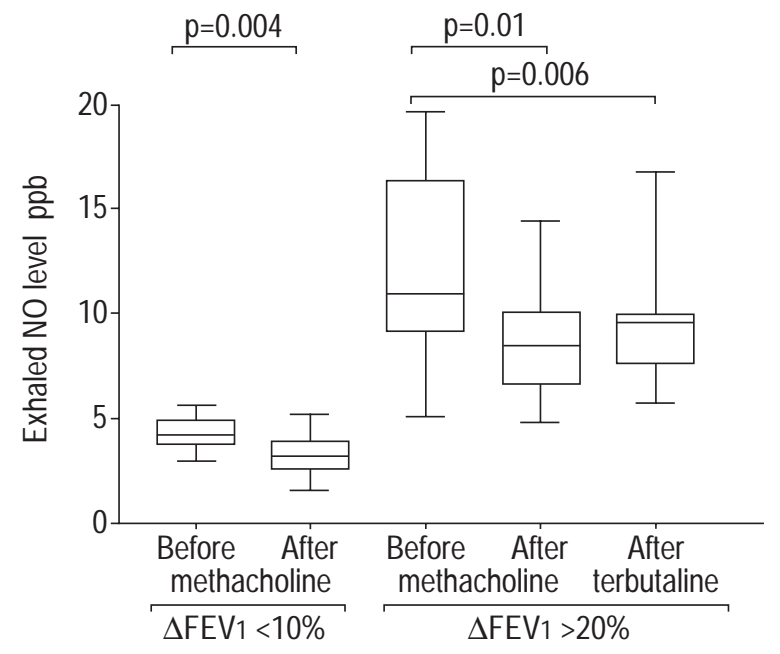

Fig. 4. - Exhaled NO levels and methacholine provocation test in the nonpollen season. Data before and after methacholine from 10 control subjects with $<10 \%$ decline in forced expiratory volume in one second (FEV1) and from 10 allergic rhinitis subjects with $>20 \%$ decline in FEV1, as well as after terbutaline in the latter group.

\section{Discussion}

In this study, a higher concentration of exhaled $\mathrm{NO}$ was found in subjects with allergic rhinitis, compared with normal controls in the nonpollen season. A further increase was seen during the pollen season. Subjects with perennial sensitization did not show the same degree of increase between the seasons as seasonal sensitized subjects, mainly due to a higher exhaled $\mathrm{NO}$ baseline in the nonpollen season. Surprisingly, nasal NO concentration was not significantly different in subjects with allergic rhinitis and normal controls in the nonpollen season, and the minor increase between nonpollen and pollen season was not significant.

The increased concentration of exhaled NO during the pollen season in allergic rhinitis is in agreement with that reported by MARTIN et al. [15], but is in contrast with that reported from another study of subjects with allergic rhinitis by KHARITONOv et al. [16]. In that study, exhaled NO concentration during the pollen season in untreated subjects with seasonal allergic rhinitis without clinical asthma was not significantly different from control subjects. The increase in exhaled NO in the present study cannot be explained, as all subjects denied asthma-like symptoms in the pollen season, and only four of them had bronchial hyperresponsiveness to methacholine. All the subjects had rhinitis symptoms and were on treatment with oral antihistamines at the time of measurement.

The increased concentration of NO in exhaled air in allergic rhinitis is suggestive of an increased production of $\mathrm{NO}$ in the lower airways. Factors known to influence the concentration of exhaled NO, such as a history of asthma or asthma-like symptoms, current smoking and acute upper and chronic lower respiratory tract infections were absent in both the control and allergic rhinitis groups. Contamination of the exhaled air by NO-rich air from the nasal cavity is unlikely, as the soft palate elevates when expiration is performed against a resistance $[17,18]$. Furthermore, a bronchoscopic study in asthmatics has indicated that the exhaled NO concentration measured in the end-tidal phase of expiration is mainly derived from the lower respiratory tract [17]. By the use of ventilation scintigraphy, O'RioRDAN et al. [19] have demonstrated that bronchoprovocation testing with methacholine causes a substantial decrease in peripheral airway ventilation in both hyperresponsive and nonhyperresponsive individuals, thus decreasing the amount of alveoli communicating with the central airways. In the present study, the concentration of exhaled NO is significantly reduced after methacholine provocation both in nonhyperresponsive controls and in hyperresponsive subjects with allergic rhinitis. Together with a concomitant decline in the concentration of exhaled $\mathrm{CO}_{2}$ (fig. 5), the decline in exhaled NO concentration after methacholine provocation further suggests that the measured NO in exhaled air really is derived from the lower airways and also that a significant amount of NO is produced in the peripheral airways.

The clinical significance of an increased concentration of exhaled NO in the nonpollen season in allergic rhinitis with both seasonal and perennial sensitization remains to be clarified. Although it is not known whether perennial sensitization compared with seasonal sensitization is associated with a greater risk for later development of asthma, a significantly higher prevalence of bronchial hyperresponsiveness to methacholine and a significantly lower FEV1 in this group in the nonpollen season, compared with controls was found. Interestingly, in nonhyperresponsive
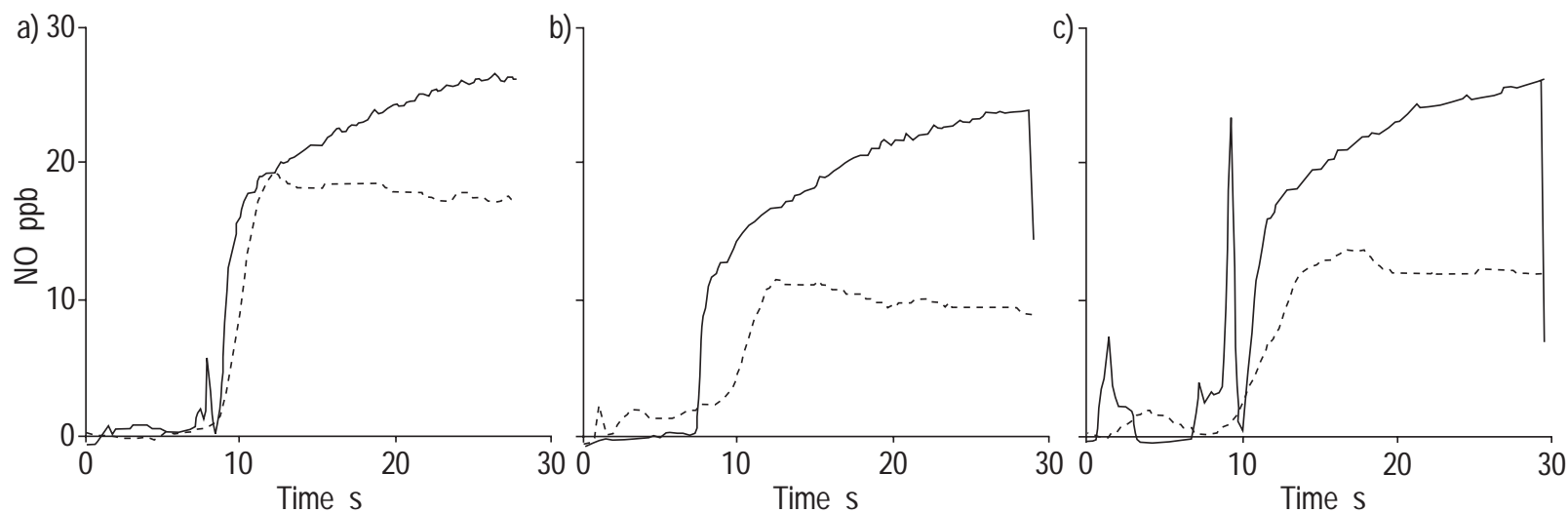

Fig. 5. - Exhaled NO (- - - ) and $\mathrm{CO}_{2}(-)$ from an allergic rhinitis subject with bronchial hyperresponsiveness to methacholine. a) at baseline; b) after methacholine provocation; and c) after bronchodilation with terbutaline. Note the decline in exhaled $\mathrm{NO}_{\text {and }} \mathrm{CO}_{2}$ after methacholine-induced bronchoconstriction, with partial reversal of decline after treatment with terbutaline. 
subjects, the baseline exhaled NO concentration is significantly greater in those subjects with both seasonal and perennial sensitization than in those with seasonal sensitization only. Furthermore, exhaled NO correlates, albeit weakly, with bronchial responsiveness in hyperresponsive subjects. If an elevated exhaled NO is associated with airways inflammation, there may be chronic inflammation in the lower airways in allergic rhinitis. The consequence of such chronic inflammation is unclear, but a close relationship between allergic sensitization to house-dust mite allergen and increased bronchial responsiveness to methacholine has been reported by OMENAAs et al. [20] in a large-scale epidemiological survey in adults in a Norwegian community. These workers also found that sensitization to this antigen was an independent predictor of lung function [21], while continual exposure of atopic individuals to low doses of allergen increases bronchial responsiveness to histamine and may be associated with an increased risk of developing asthma [22]. Thus, in addition to being a potential marker of airway inflammation in asthma, the concentration of exhaled NO may well be a potential prognostic marker for identifying those with allergic rhinitis who may be at risk of developing asthma.

The absence of a significant increase in nasal NO during the pollen season is in contrast to that found in other studies $[15,16]$. This may be due to nasal congestion with reduced passage of NO-rich air through the paranasal ostia. Acute nasal congestion induced by nasal challenge with grass pollen extract reduces nasal NO levels in atopic individuals, and nasal NO levels have been shown to correlate negatively with symptom scores [16].

In summary, it was demonstrated that in allergic rhinitis exhaled nitric oxide is significantly elevated, and increases on allergen exposure. The baseline production of exhaled nitric oxide is increased in subjects with hyperresponsiveness and in subjects with both seasonal and perennial sensitization. The clinical importance of these findings is unclear, but it would be interesting to speculate that sensitized subjects with elevated exhaled nitric oxide levels who have or subsequently develop increased bronchial responsiveness to methacholine on continuous allergen exposure are at an increased risk for the development of asthma. This hypothesis should be addressed in future prospective studies.

Acknowledgements. The skilful technical assistance of T. Skaland, R. Fostad, H. Fossland and B. Pedersen is greatly appreciated.

\section{References}

1. Braman SS, Barrows AA, DeCotiis BA, Settipane GA, Corrao WM. Airway hyperresponsiveness in allergic rhinitis: a risk factor for asthma. Chest 1987; 91: 671-674.

2. Ramsdale EH, Morris MM, Roberts RS, Hargreave FE. Asymptomatic bronchial hyperresponsiveness in rhinitis. J Allergy Clin Immunol 1985; 75: 573-577.

3. Madonini E, Briatico Vangosa G, Pappacoda A, Maccagni G, Cardani A, Saporiti F. Seasonal in crease of bronchial reactivity in allergic rhinitis. $J$ Allergy Clin Immunol 1987; 79: 358-363.

4. Pipkorn U, Proud D, Lichtenstein LM, Kagey Sobotka A, Norman PS, Naclerio RM. Inhibition of mediator release in allergic rhinitis by pretreatment with topical glucocorticosteroids. N Engl J Med 1987; 11: 1506-1510.
5. Aubier M, Levy J, Clerici C, Neukirch F, Herman D. Different effects of nasal and bronchial glucocorticosteroid administration on bronchial hyperresponsiveness in patients with allergic rhinitis. Am Rev Respir Dis 1992; 146: $122-126$.

6. Corren J, Adinoff AD, Irvin CG. Changes in bronchial responsiveness following nasal provocation with allergen. J Allergy Clin Immunol 1992; 89: 611-618.

7. Littell NT, Carlisle CC, Millman RP, Braman SS. Changes in airway resistance following nasal provocation. $\mathrm{Am}$ Rev Respir Dis 1990; 141: 580-583.

8. Kharitonov SA, Barnes PJ. Nitric oxide in exhaled air is a new marker of airway inflammation. Monaldi Arch Chest Dis 1996; 151: 533-537.

9. Kharitonov SA, Yates D, Barnes PJ. Increased nitric oxide in exhaled air of normal human subjects with upper respiratory tract infections. Eur Respir J 1995; 18: 295297.

10. Alving K, Weitzberg E, Lundberg JM. Increased amount of nitric oxide in exhaled air of asthmatics. Eur Respir $J$ 1993; 6: 1368-1370.

11. Kharitonov SA, O'Connor BJ, Evans DJ, Barnes PJ. Allergen-induced late asthmatic reactions are associated with elevation of exhaled nitric oxide. Am J Respir Crit Care Med 1995; 151: 1894-1899.

12. Kharitonov SA, Yates DH, Barnes PJ. Inhaled glucocorticoids decrease nitric oxide in exhaled air of asthmatic patients. Am J Respir Crit Care Med 1996; 153: 454-457.

13. O'Connor GT, Sparrow D, Weiss ST. Normal range of methacholine responsiveness in relation to prechallenge pulmonary function. The Normative Aging Study. Chest 1994; 105: 661-666.

14. Kharitonov SA, Alving K, Barnes PJ. Exhaled and nasal nitric oxide measurements: recommendations. Eur Respir $J$ 1997; 10: 1683-1693.

15. Martin U, Bryden K, Devoy M, Howarth P. Increased levels of exhaled nitric oxide during nasal and oral breathing in subjects with seasonal rhinitis. $J$ Allergy Clin Immunol 1996; 97: 768-772.

16. Kharitonov SA, Rajakulasingam K, O'Connor BJ, Durham SR, Barnes PJ. Nasal nitric oxide is in creased in patients with asthma and allergic rhinitis and may be modulated by nasal glucocorticoids. J Allergy Clin Immunol 1997; 99: 58-64.

17. Kharitonov SA, Chung KF, Evans D, O'Connor BJ, Barnes PJ. Increased exhaled nitric oxide in asthma is mainly derived from the lower respiratory tract. $\mathrm{Am} \mathrm{J}$ Respir Crit Care Med 1996; 153: 1773-1780.

18. Silkoff PE, McClean PA, Slutsky AS, et al. Marked flowdependence of exhaled nitric oxide using a new technique to exclude nasal nitric oxide. Am J Respir Crit Care Med 1997; 155: 260-267.

19. O'Riordan TG, Walser L, Smaldone GC. Changing patterns of aerosol deposition during methacholine bronchoprovocation. Chest 1993; 103: 1385-1389.

20. Omenaas E, Bakke P, Eide GE, Elsayed S, Gulsvik A. Serum house dust mite antibodies: predictor of increased bronchial responsiveness in adults of a community. Eur Respir J 1996; 9: 919-925.

21. Omenaas E, Bakke P, Eide GE, Elsayed S, Gulsvik A. Serum house-dust-mite antibodies and reduced FEV1 in adults of a Norwegian community. Am J Respir Crit Care Med 1995; 152: 1158-1163.

22. Gabrielsson S, Paulie S, Roquet A, et al. Increased alergen-specific Th2 responses in vitro in atopic subjects receiving subclinical allergen challenge. Allergy 1997; 52: $860-865$. 